\title{
6. Anatomical Reading of Correspondence: A Case Study of Epistolary Analysis Networks
}

KATHERINE COTTLE

The recent transition from paper to electronic form as the standard means of communication has shifted not only the medium of epistolary expression, but also the networking potential of scholars and historians. Visualizations of networks can no longer rely solely on humanistic expectations of time, space, direction, and location with regards to communication, even when reading and studying text from pre-digital times. As personal print text becomes more and more indistinguishable from public digital communication, we find ourselves at a crossroads in finding appropriate venues for representing words that relate "a momentary experience which incorporates but stands outside orthodox conceptions of material and immaterial existence."1

How do we, as current correspondents, scholars, and researchers, imbed standardized networking frameworks, such as traditional mapping, into current and future networking needs and applications? How can data-driven networks help to increase accessibility and knowledge of past figures and texts while simultaneously sustaining humanistic foundations, ethics, and aims? The Viral Networks workshop provided the time, physical and virtual space, guidance, and digital resources for me to explore these questions through networking applications of a recently discovered archive of personal correspondence, "The Esther Richards Letters, 1915-1932," included within my forthcoming book, The Hidden Heart of Charm City: Baltimore Letters and Lives (AH/ Loyola University Maryland). 
My immediate urge with the project was to map Richards's letters through a network which existed at the time frame of the letters' origination (1915-1932), like this United States Post Office map:

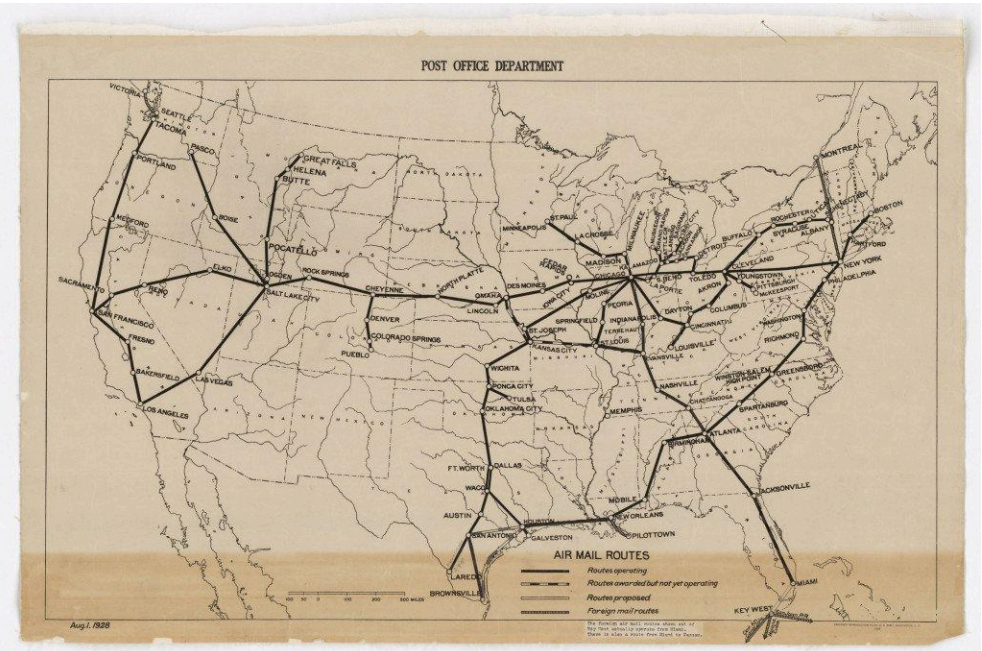

Figure 6.1: Post Office Department map of air mail routes, August $1928^{2}$

However, it did not take me long to realize that my current students-our future scholars and researchers-already view traditional mapping (and the postal system) as outdated and disconnected from their understanding of communicative networks. My visualizations, to be relevant and engaging to future readers, needed to apply networking in a more presence-centered framework. Therefore, instead of trying to find a compromise-between physical and digital lenses-in networking visualizations of epistolary correspondence, I choose to utilize a hybrid humanistic/data-driven structure for my diagrams. I constructed an anatomical reading networking series-a conceptual reading approach that combines surface-level views of letters with network applications which reach below the surface of text in ways only possible by digital analyses. The letters in the "Esther Richards Letters" archive were ideal for this project, as the correspondence written by Dr. Esther Loring Richards, "psychiatrist-in-charge of the outpatient department of the 
Phipps Clinic from 1920 until her retirement in 1951,"33 contains structural and content patterns reflective of an unorthodox woman utilizing words to find support, companionship, and enlightenment within fields and academic realms often deemed incompatible-approximately one hundred years before I found myself making the same attempts, in the same city.

Richards's letters are addressed to Dr. Abby Howe Turner, Richards's former professor, and these letters are contained within a digital archive devoted entirely to Mount Holyoke College. Richards's letters to Turner have only been accessible to the public since 2005. Due to the personal and voluntary efforts of Mount Holyoke alum, Donna Albino, viewers across the world can now see and read the dedicated and prolific communication of many early women in American science connected to Mount Holyoke College. ${ }^{4}$ Albino's online archive showcases the need of women in early American science to find personal and written support and companionship outside of their individual medical communities and higher education institutions.

Correspondence networks, as evidenced in Albino's archive, were the primary communicative routes which enabled pioneering women such as Richards and Turner to endure the isolation, uncertainty, biases, and challenges of higher education institutions and medical communities to become pivotal figures in early American science. The Viral Networks workshop enabled a deeper view of the words, places, and people within these correspondence networks. Through macroscopic and microscopic anatomy readings, we see Richards, and ourselves.

Macroscopic Anatomy The examination of relatively large structures and features usually visible with the unaided eye, including surface, regional, systemic, and developmental anatomies.

Attentive readers are quite able to make thoughtful observations and analyses without the assistance of digital enhancement. Correspondence structures which lend themselves to macro-level 
networks might include surface-level reading (words and inventories), regional-level reading (locative information to showcase the importance of place), systemic-level reading (societal frameworks), and developmental-level reading (a combination of surface, regional, and systemic reading via developing institutions and histories).

\section{Surface Reading}

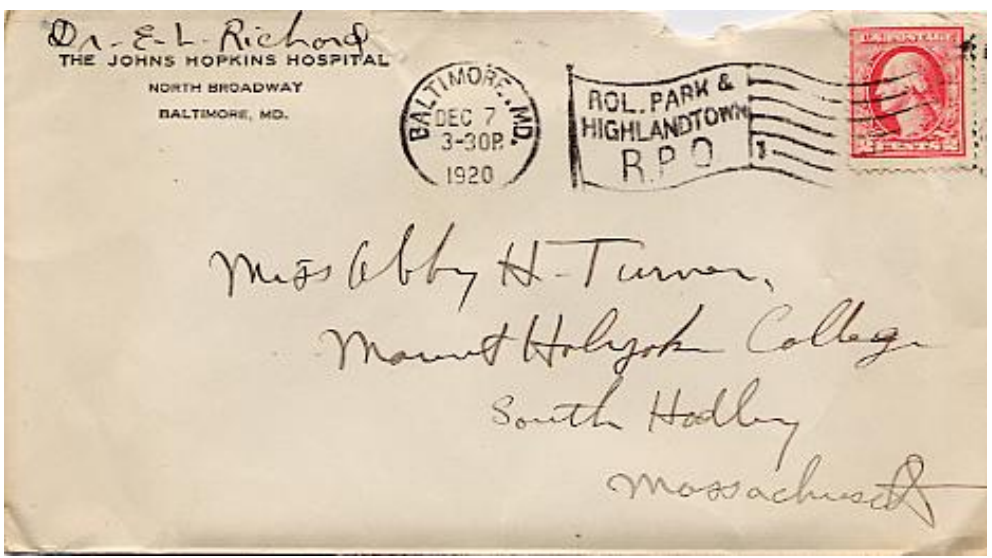

Figure 6.2: Envelope of letter addressed to Miss Abby H. Turner from Dr. E.L. Richards 5

A surface, inventory-based reading of the Richards/Turner letters' archive reveals an intimate and long-term epistolary network and relationship which began at Mount Holyoke College, where Richards graduated with an A.B. degree in $1910,{ }^{6}$ and where Turner founded and taught within the physiology department from 1896-1940. ${ }^{7}$ Richards's preserved letters to Turner date from 1915-1932, the years during which Richards was a graduate student and then faculty member at Johns Hopkins Hospital. ${ }^{8,9}$ Albino has listed each preserved letter by date, with links to digital visuals of available addressed envelopes, partial letter scans, and transcriptions of content. There are a total of 42 letters presented on the webpage 
"The Esther Richards Letters, 1915-1920" and 49 letters presented on the webpage "The Esther Richards Letters, 1921-1932." 10, 11 Turner's letters to Richards are not preserved, though hundreds of Turner's letters to other peers/early women in American science are preserved and accessible in the "Abby Howe Turner 1896" section of Albino's website. ${ }^{12}$

The amount and depth of the Richards/Turner letters, viewed within the scope of so many other personal epistolary exchanges of academic women from the late 1800s and 1900s, immediately highlights the prolific writing habits and dedicated unions of these women, especially in providing consistent communication and support across state lines, decades, and career fields. Even without extensive and in-depth critical examination and analysis, a surface reading of the Richards/Turner letters, and the archive as a whole, showcases the role of words as a foundation for correspondence networks which began as academic relationships, yet quickly branched into the lives, places, and projects inspired by Mount Holyoke's early mission to "[g]o where no one else will go, do what no one else will do."13

Readers can easily navigate Albino's organized and link-based website: a network of female connections inspired by Albino's own role as an alum, a preserver, and a tributary in sharing access to the behind-the-scenes lives of women in early American science. Surface reading is vital for textual analysis, not only as an inventorybased assessment, but also to establish a set of artifacts, a foundational framework, and an accessible range of material. Albino's website provides these elements for an examination of the Richards/Turners letters; however, immediate voids within surface reading are notable due to missing correspondence (all of Turner's correspondence to Richards and potential missing correspondence from Richards to Turner), human error (in transcription and translation), and accessibility (economic and temporal realities). 


\section{Regional Reading}

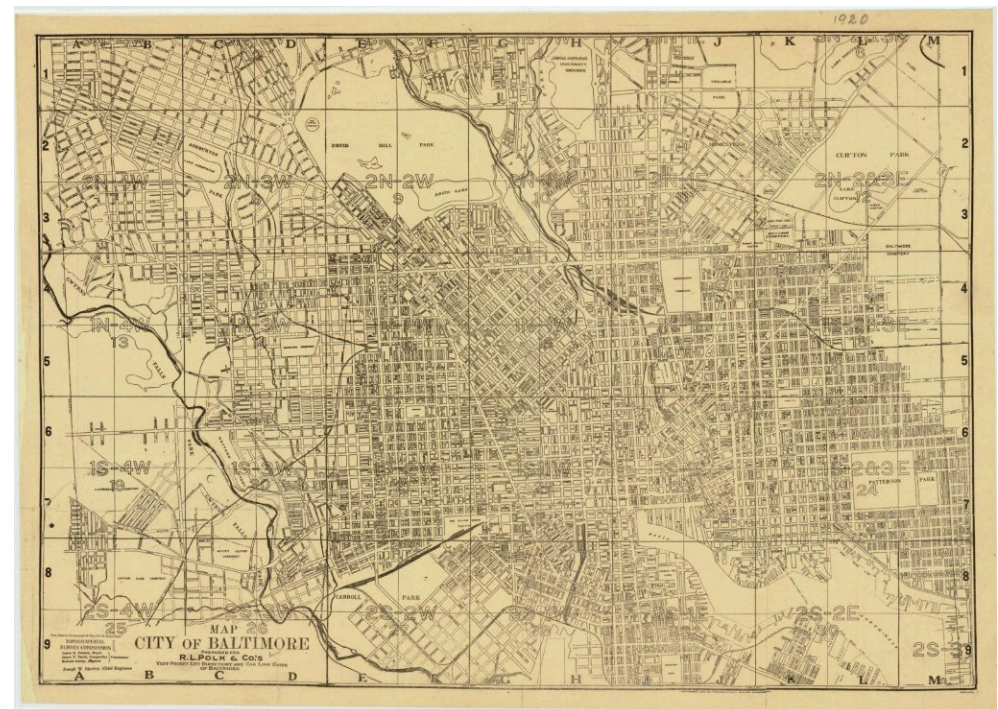

Figure 6.3: 1920 Baltimore City Directory ${ }^{14}$

Just below the surface level of the Richards/Turner correspondence, additional regional networks quickly emerge which strengthen geographical reading connections. Richards writes to Turner at "Mount Holyoke College, South Hadley, Massachusetts"15 from "Johns Hopkins Hospital, North Broadway, Baltimore, MD." ${ }^{16}$ Johns Hopkins Hospital's role in the Baltimore community is notable, beginning with its pronounced return address on Richards's envelope. Early on in her employment at the Phipps Clinic, Richards recounts a local Baltimore preacher's words in her February 27, 1916, letter to Turner, expressing anger at the preacher's doubt of the hospital's psychiatry program legitimacy: "The Rev. said 'If Onesimus had lived in Balt. today people would have considered him the product of his heredity \& environment, \& sent him to the Phipps Clinic to be investigated.' That made me hot 
too."17 Richards's emotions guide her portrait of Baltimore, painting a combustive picture of a city grappling with poverty, health issues, institutional dysfunction, and cultural shifts.

Due to Richards's regional outsider status, her words depict a different geographical network from that of an insider, especially regarding Johns Hopkins Hospital and its immediate surroundings. "It has been warm here," Richards writes to Turner on August 7, 1917, "but the patients have not minded it much. You see they are southerners."18 While adjusting to living in a warmer climate than her native New England, Richards's early correspondence to Turner often refers to the humidity and physical drain of Maryland's summer months. Richards's August 7, 1917, letter admits that "[t]he heat is so hard on your spirit, I know from past summers." ${ }^{19}$ The mid-Atlantic seasons not only appear in the content of the correspondence, but also in their reflection of a medical career which is consistently and constantly cycling, blurred with the weight of perpetual precipitation, transition, and challenge. Baltimore is a place, Richards reinforces on August 7, 1917, where "the children have suffered fearfully, \& their lives are snuffed out easily." $^{20}$

Richards's mapping of Baltimore includes paths into Johns Hopkins Hospital not found on street signs or directories-a preserved region of the children she hears "cry[ing] at night, and in the daytime when they trudge by the clinic over the hot \& dusty walk" ${ }^{21}$ - transporting routes only revealed in an epistolary key. While regional readings of correspondence help to widen the internal and external geographical networks connected to sender and receiver endpoints, such as Baltimore's Johns Hopkins Hospital and South Hadley's Mount Holyoke College in the Richards/Turner letters, analysis is limited to locative-based markers. Mappings moving into more metaphorical and conceptual frameworks may need to dig deeper into epistolary anatomies. 


\section{Systemic Reading}

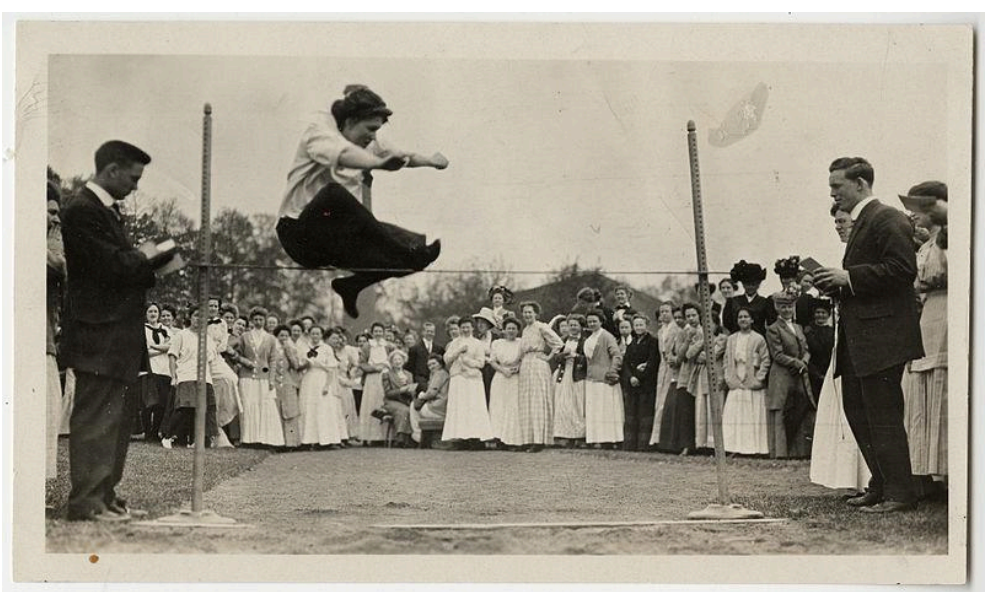

Figure 6.4: "Photograph of Anne Hall, Mount Holyoke College Class of 1910, high jumping on May 11, 1910. The meet was officialled by three men from the Springfield training school."22

Uncovering the underlying systems below surface and regional views, then, exposes the people and societal frameworks controlling the words and places of existing texts. For example, Richards's letters regularly critique the gender-biased and elitist medical community in Baltimore, as well as the country at large. Richards's earliest archived letter, sent to Turner on March 10, 1915, while Richards was still a graduate student, describes her displeasure at a conversation at a recent Johns Hopkins Medical dinner, in which the hostess "told [Richards] [h] ow many maids she carried abroad with her when she first went after marriage." 23 This early glimpse of Hopkins society is a bitter pill Richards must swallow in order to carve out her reputation as a woman in early American science. Her correspondence to Turner provides a place for unfiltered venting about Baltimore's upper class, especially those in high ranking positions at Hopkins. Richards's March 10, 1915, letter to Turner ends 
with a perfect example of such elitism, a quote from the Hopkins dinner hostess: "She was interested to know how I survived such close \& continuous contact with the "masses."'24

Richards's outsider status, not just in terms of her home region, but also in terms of her gender and class, influences many of her letters to Turner. Richards often relays variations of her message written on September 4, 1920: "[t]he battle with me is pretty much alone." ${ }^{25}$ Within this long-term state of isolation, Richards's armor becomes the words and letters exchanged between herself and Turner, in addition to her communication with other female peers and friends, many originating from her time at Mount Holyoke College. Richards's September 4, 1920, letter to Turner is clear in its declaration of the correspondence necessity for her survival: "Please write me often. I need your letters." ${ }^{26}$ The network of letters from women provides Richards with the support and validation that she neither receives from Johns Hopkins Hospital, nor from medical communities elsewhere in the nation, even while being one of their pivotal figures.

Richards's words to Turner on September 29, 1924, still ring with her anger: "How slip-shod they do things at the Harvard Medical \& that nice discrimination against our sex! Pleasant isn't it. I've often longed to put a bomb under that noble University, blow it sky high, \& begin again with something less conservative \& aristocratic." ${ }^{27}$ Free from career and collegiate restraints and requirements in the epistolary form, Richards can critique the male-dominated, elitist medical field without fear of retaliation.

Ironically, Richards's correspondence to Turner becomes its own medical university curriculum proposal, enabled, because of its unique genre status, to exist separate from the systemic inequities of Richards's and Turner's time. Clearly organized, defended, and debated back and forth across multiple states-for close to two decades, Richards's desired medical university is only found on paper, its "less conservative \& aristocratic" ${ }^{28}$ elements tucked neatly inside envelopes, its enrollment limited to two corresponding members. While systemic readings unveil larger conceptual 
anatomies of text and help to place surface and regional elements into context, they are also filtered through the systemic influences of the reading time period. Current biases and preferred scholarly lenses will look obvious only a few years into the future, and analyses will date themselves almost immediately upon presentation and/or publication.

\section{Developmental Reading}

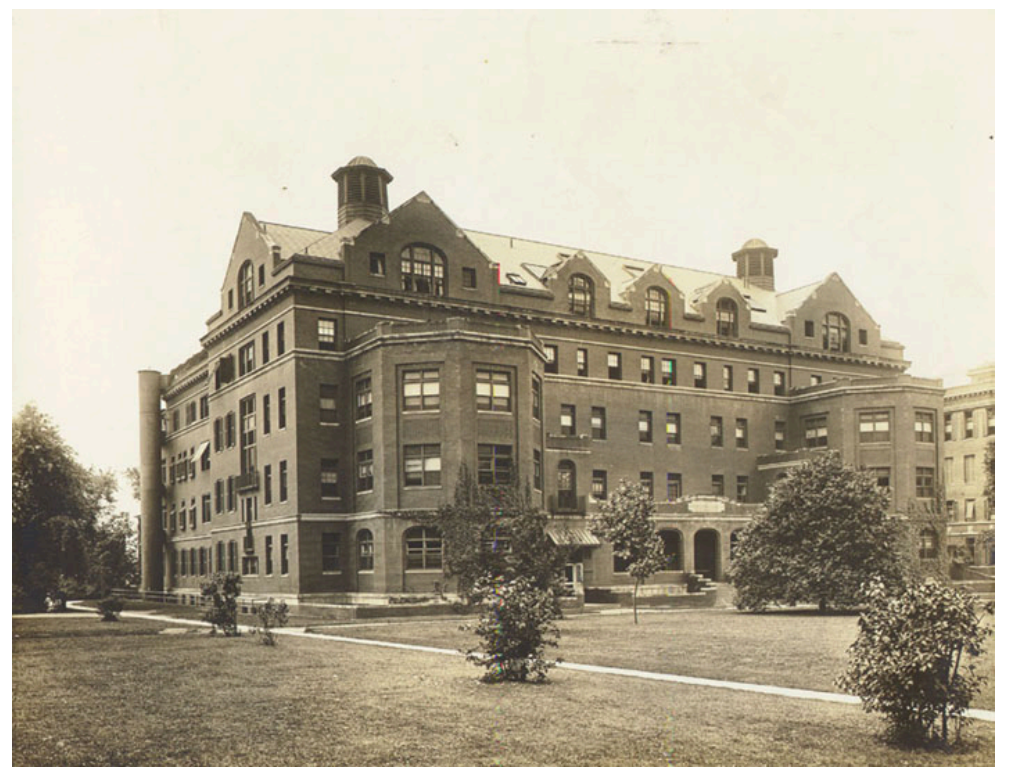

Figure 6.5: Henry Phipps Psychiatric Clinic, Johns Hopkins Hospital ${ }^{29}$

The networks of scientific advancements, psychiatry trends, global military action, and religious and cultural shifts happening in the first decades of the twentieth century provide examples of the fluid nature of epistolary analysis in the Richards/Turner correspondence, showcasing fluctuating views of society that often cannot be seen or found in traditional non-epistolary sources. 
Within these macro-levels of reading-surface, regional, and systemic-networks of words, places, and people coincide and are visible in developing institutions and their developing histories.

Richards, the once idealistic pioneering female student, gradually grows disenchanted with her former alma mater, the psychiatry field, and "the masses." Her February 22, 1917, letter admits that "[Mount Holyoke] seemed ideal when I left 7 yrs ago, and now it might suffocate me if I stayed there long enough." ${ }^{30}$ Richards's desire for humanistic connection and faith increases as she ages, and Richards often relates her analysis of the current state of the country to Turner, as seen in her February 13, 1932, letter: "Education does not educate emotions of selfishness, \& greed \& Ego striving. Only the Grace of God does that, \& people don't believe in that any more. We are sold to service \& culture. ${ }^{31}$ Even with Turner's missing correspondence, Richards's portion of the communication exposes a search for identity, meaning, and integrity as the world develops and changes around her and the other women trained and based in late nineteenth and early twentieth century customs and ideologies.

Yet, the developments of Richards's and Turner's epistolary network fostered the communication, analysis, criticism, and growth necessary to directly support them, as well as to indirectly bridge opportunities and advancements to other women in early American science, as noted in many letters in which early American sister schools are referenced. For example, Richards's February 17, 1920, letter updates Turner on a newly formed alum organization at Johns Hopkins and an education rally "in conjunction with Smith, Goucher, Mt. H., Bryn Mawr for endowment campaign interest."32

Over a century later, Richards's preserved personal correspondence to Turner (and Turner's unpreserved personal correspondence to Richards) remains the clearest evidence of their personal relationship and the communicative support necessary for them to sustain long-term careers as women in early American science, yet their account remains missing from standardized histories and publications, as it does for so many other women, 
unless voluntarily brought to the surface. Macro-level reading and analysis provide further evidence of this neglect; however, this analysis often stops just below the surface, due to humanistic limits. Through the use of data-driven visual networks, further views of words, places, and people are better able to be revealed, helping to widen the scope of perspective, proof, and connection.

\begin{abstract}
Microscopic Anatomy The examination of structures involving the use of optical instruments, including histology (the study of tissues), and embryology (the study of an organism in its immature condition).
\end{abstract}

Through digital networks, readers may identify layers incapable of being penetrated by humanistic practices and utilize visuals to further support, refute, or develop existing analyses. As with any anatomical surgery, expectations are often shifted and/or transformed with surprising discoveries and co-morbid findings. By combining micro-level digital analysis with macro-level critical analysis, correspondence reading becomes not only an accountable set of word, place, and people networks which connected via the postal system, but the correspondence also forms an intricate network of literary tissues which document and connect underlying and preferential choices, topics, and relationships.

\title{
Embryology Reading
}

An embryology reading presents the opportunity to break down the correspondence to its most immature condition: a list of individual words. The process of creating a word inventory for any large set of text-without digital support-is undesirable for most readers. The time, effort, and consistency needed to count and chart the words contained within the 91 letters in the Richards/Turner correspondence archive is daunting and out of reach for most readers. Data analytics, however-and word cloud diagrams in particular-provide not only an accurate and speedy inventory 
count of words, but also the potential for visual representations which can quickly expose the frequency of words in a comparative structure.

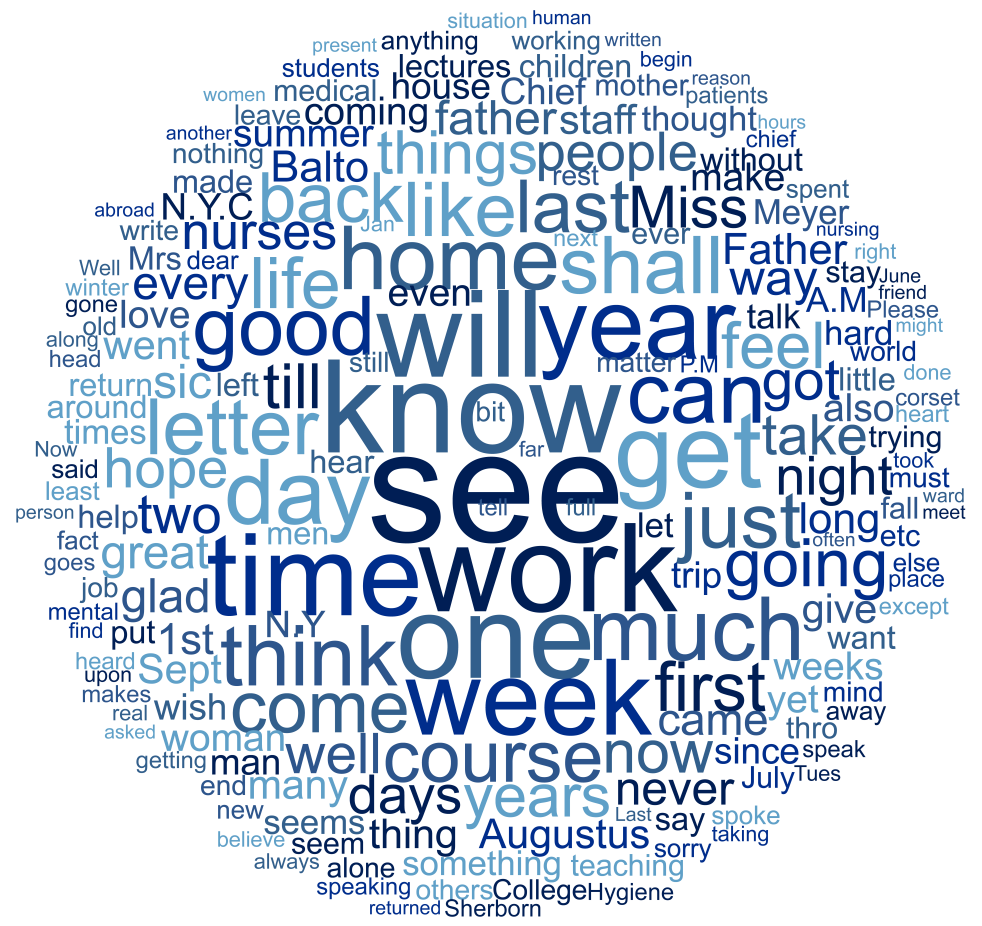

Figure 6.6: 200 Most Common Words in Letters from Dr. Esther Loring Richards to Dr. Abby Howe Turner, 1915-1932

Full text of all of the letters in the Richards/Turner correspondence were downloaded digitally and processed using Python. ${ }^{33}$ A word cloud (above) was generated based on word frequency in the entire corpus of letters. ${ }^{34}$

Immediately, readers can see patterns in the frequency of words in the Richards/Turner correspondence, especially concerning time and actions. A quick glimpse at the Richards/Turner correspondence high-frequency word cloud reveals "year," "day," "time," "week," "till," and "first" to be dominating words within the 
correspondence. While date-related references surely do not surprise in postal correspondence, the frequency and range of such words clearly emphasizes the important role of time in the letters and Richards's and Turner's lives. Short-term and long-term temporal qualifiers are matched in their usage and importance throughout the correspondence.

Action words are also frequently utilized, such as "see," "know," "work," and "think." "See" is Richards's most repeated word, incorporated in her letters to Turner as a physical-based desire for vision, as noted in her February 27, 1916, letter ("I wish you were nearer that I might see you once in awhile"); an observation of condition, as expressed in her May 13, 1920, letter ("Whereas I see in patients \& people at large a dozen other twists of personal behavior that are just as \& even more serious in their results"); and an understanding of situation, as shown in her December 23, 1919, letter ("It is easy to see why she has been discriminated against"). ${ }^{35}$

The frequency of "one," is also quite notable-as a number, as evident in Richards's September 15, 1922, letter ("We have on our wards one of Mildred Gutterson's sisters - a Mrs. Smith"); as a nonspecific person, as seen in her October 20, 1921, letter ("One must consider not only the 4 years of confining study, but also the 4 more years of hospital apprenticeship, after which one enters the field of practise to begin the real struggle in competition"); as a societal entity, as viewed in her May 31, 1922, letter ("Caring is a quality that one cannot put into a human being"); and as a pronoun referent, noted in her March 21, 1915, letter ("Ruth Guy has one [a cold], as well as [a] girl in my own class"). ${ }^{36,37}$

An embryology reading's strengths rely on the presentation of high frequency words through digital analytics. The ability to quickly and accurately compile word frequency lists in visual format is invaluable when a reader is interested in confirming a critical analysis assumption. As with any inventory-based analysis, an embryology reading's strengths rely on the presentation and the histories, preferences, experiences, and desires of the reader. High frequency count signals repetition, but that repetition does not 
necessarily represent content or analytical significance, as was noted from the need to remove non-stop words before performing the data analytics necessary to make a meaningful word cloud and the range of meanings and/or parts of speech for any individual word.

\section{Histology Reading}

By using computer algorithms to detect underlying topics in a corpus of work and cluster words based on their association with each topic, readers can view unpreserved movements and correlations between words, similar to the unpreserved motions between mailed letters, time spans between correspondence receipts, and actions between communications. An histological reading, only possible through the micro-level ability of network data processing, starts to reveal the forces supporting the words in preserved correspondence: the tissues holding a large body of work together.

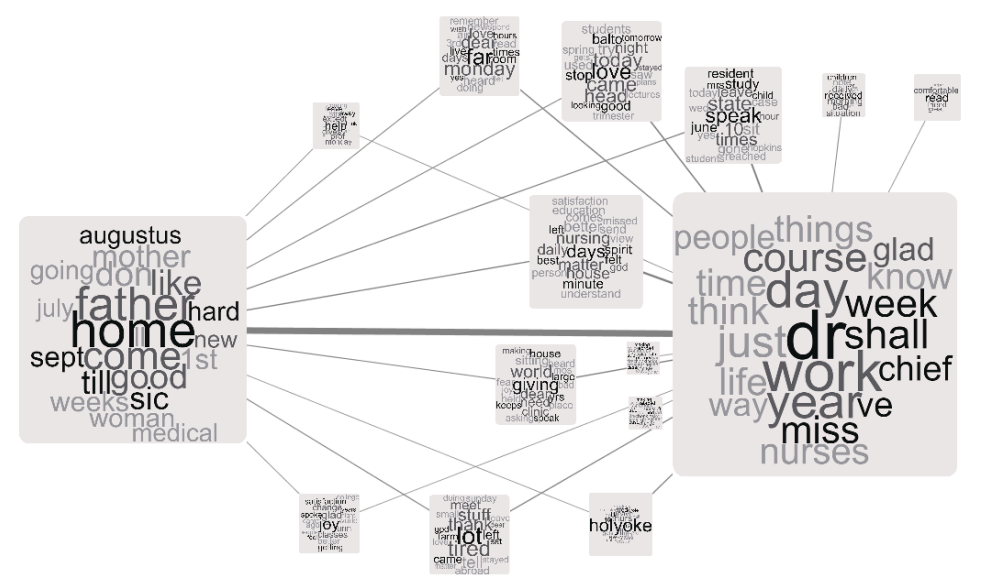

Figure 6.7: 200 Network of Topics and High-Importance Words by Topic in Richards/Turner Letters 
Topics within the Richards/Turner correspondence were inductively detected using a technique known as Latent Dirichlet Allocation (LDA). LDA groups words that frequently appear together in the same sources (e.g. letter) and are less frequently paired with other words. ${ }^{38}$ Topic Frequency-Inverse Document Frequency (TFIDF) weighting was used prior to constructing the topic model to increase the relative weight of words in documents where they appear most frequently. The network and visualization were constructed in Cytoscape. Larger nodes represent distinctive topics, whereas the words in smaller nodes are spread fairly evenly throughout the sources. The thickness of each edge is based on how closely the pair of topics are connected by occuring in similar sets of sources.

Immediately, an amplified connection is apparent between the topical groupings revolving around "home" (including "father, "come," "good," "mother," "hard," "sept", "weeks") and "dr" (including "work," “day," “year," "course," "miss," "nurses," "people," "life," and "chief"). The role of time-through "days," "weeks," or "years"-is revealed to be a common thread in both of the largest distinctive topics, whether private or public in their focus.

Other secondary-level distinctive topic tissues include strong relationships between the topics "speak"/"state"/"10" /"times" and "days"/"nursing"/"matter"/"better." Topical grouping around "holyoke" and "hopkins" are not central in this networking visual, but rather secondary and tertiary in their placement. "Hopkins" is viewed, in small significance of high frequency topic connection, in several of the groupings, while "holyoke" stands out as highly frequent and closely connected to "dr" and "home."

Strengths of using histological networking for topic analysis are evident in the visual's ability to demonstrate relational connections and influence both within and across topics. Degrees of connection and force are capable of being perceived and recorded as part of a larger picture of others' writing processes and products. Yet, human assumptions are still inevitable in our own documenting processes to create these products, and individually-preferred choices and 
limits must be made when selecting data for entry and exit analysis. Still, this type of micro-level networking provides a cohesive view of long-term correspondence which has been previously impossible to capture-a view which documents the people and places between the words.

\section{Conclusion}

Anatomical networks provide surface, underlying, and data-driven views of words, places, and people which expose multiple layers of human experience. As with any series of analyses, including those that are medical based, multiple scans are often necessary to see external and internal components; layered views enhance readings, analyses, and networks of historical text. Macro- and micro-level readings, therefore, need not be performed in exclusion of one another, especially when analyzing personal correspondence. As network technology and humanity continue to advance, so do developments and options for further study, identification, connection, and understanding between words, places, and people. Yet, as Richards herself warns Turner in her November 26, 1917, letter, we must not devalue the human spirit and vision in this process: "The great trouble with many scientific giants today is that they grow enslaved by what they can grow in a test tube, by what they can see thru' a microscope, or do with electricity." ${ }^{39}$

Another major challenge of validating correspondence-based anatomical networks is that the majority of personal communication is not, nor will it ever be, digitized, transcribed, or accessible to the public. We are also still in the early stages of archiving epistolary texts, due to the relatively recent partial extinction of the print letter, new standards of communication modes, the time-consuming and costly transfer of private letters into publicly accessible digital archives, and the necessary but difficult conversations about the most appropriate and ethical methods for representing past networks in present visuals. Still, 
as Anais Nin famously noted, "we [continue to] write to taste life twice: in the moment and in retrospect, ${ }^{40}$ and in parallel effort, we must continue to utilize unfolding technologies to create multiple networks to simultaneously view the past and the present-words and patterns that need the eye and the equation to more fully and accurately "see" the bodies of our epistolary selves.

\section{Acknowledgments}

Preliminary research for this project was supported by my dissertation committee at Morgan State University (Julie Cary Nerad, Joy Myree-Mainor, Frank Casale, and Dolan Hubbard), the National Endowment for the Humanities, and the National Library of Medicine. Additional gratitude is due to Mount Holyoke graduate, Donna Albino, and her efforts to increase accessibility and appreciation for early American women in science and their letters. The opinions, findings, and conclusions do not reflect the views of the funding agencies, cooperating institutions, or other individuals. 


\section{Endnotes}

1. Dorothy A. Lander, "Love Letters to the Dead: Resurrecting an Epistolary Art," Omega: Journal of Death E Dying 58, no. 4 (2008/9): 314.

2. "Postal Office Department Map of Continental U.S. Air Mail Routes," National Archives Catalog, accessed April 15, 2018, https://catalog.archives.gov/id/6857715.

3. "The Esther L. Richards Collection," The Alan Mason Chesney Medical Archives of the Johns Hopkins Medical Institutions, accessed April 10, 2018, http://www.medicalarchives.jhmi.edu/papers/richards el.html.

4. "A Postcard Collection of Mount Holyoke College," The American Genealogy and History Project, Mount Holyoke College History, https://www.mtholyoke.edu/ dalbino/index.html.

5. Esther Richards, “The Esther Richards Letters, 1915-1920," The American History and Genealogy Project, August 8, 2013, https://www.mtholyoke.edu/ dalbino/letters/erichards1.html.

6. "Esther L. Richards Collection," The Alan Mason Chesney Medical Archives of the Johns Hopkins Medical Institutions, accessed April 10, 2018, http://www.medicalarchives.jhmi.edu/papers/richards el.html.

7. "Abby Howe Turner 1896," Mount Holyoke College, accessed April 14, 2018, https://www.mtholyoke.edu/ dalbino/women19/abby.html.

8. Richards, "The Esther Richards Letters, 1915-1920."

9. Esther Richards, “The Esther Richards Letters, 1921-1932," The American History and Genealogy Project, August 8, 2013, https://www.mtholyoke.edu/ dalbino/letters/erichards2.html/.

10. Richards, "The Esther Richards Letters, 1915-1920."

11. Richards, “The Esther Richards Letters, 1921-1932."

12. "Abby Howe Turner 1896."

13. "A Detailed History," Mount Holyoke College, accessed April 16, 2018, https://www.mtholyoke.edu/about/history/detailed.

14. "1920 City Directory,' Special Collections, Johns Hopkins University, accessed April 8, 2018, https://jscholarship.library.jhu.edu/bitstream/handle/1774.2/33836/ 1920\%20City\%20Directory\%20.jpg?sequence $=2$.

15. Richards, "The Esther Richards Letters, 1915-1920."

16. Ibid.

17. Ibid.

18. Ibid.

19. Ibid.

20. Ibid. 
21. Ibid.

22. "File:Anne Hall, Mount Holyoke College Class of 1910, high jumping..jpg," Wikimedia Commons, October 2, 2013, https://commons.wikimedia.org/wiki/ File:Anne Hall, Mount Holyoke College Class of 1910, high jumping..jpg.

23. Richards, "The Esther Richards Letters, 1915-1920."

24. Ibid.

25. Ibid.

26. Ibid.

27. Ibid.

28. Ibid.

29. “The_Henry_Phipps_Psychiatric_Clinic.jpg," Wikimedia Commons, June 21, 2016, https://commons.wikimedia.org/wiki/

File:The Henry Phipps Psychiatric Clinic.jpg.

30. Richards, "The Esther Richards Letters, 1915-1920."

31. Richards, "The Esther Richards Letters, 1921-1932."

32. Richards, "The Esther Richards Letters, 1915-1920."

33. Processing of the correspondence, topic modeling, and word cloud visualizations were created by Nathaniel Porter, in consultation with the author, to explore and demonstrate additional analytic options. Data files and code used in analysis available at doi:10.7294/284t-bf10.

34. English stopwords (very common words with minimal semantic value, such as "the") were removed before creating topic models and word clouds.

35. Richards, "The Esther Richards Letters, 1915-1920."

36. Richards, "The Esther Richards Letters, 1921-1932."

37. Richards, "The Esther Richards Letters, 1915-1920."

38. LDA does not label topics in any way; it is strictly inductive and leaves interpretation to the user, based on commonalities among the words most closely associated with each topic.

39. Ibid.

40. Anais Nin, "The New Woman," In Favor of the Sensitive Man and Other Essays (Orlando, Florida: Harcourt Brace and Co., 1994), 13. 